DOI: https://doi.org/10.12957/teias.2020.48632

\title{
AS MÍDIAS NO COTIDIANO DA EDUCAÇÃO INFANTIL NA PERSPECTIVA DOS ACADÊMICOS DO CURSO DE PEDAGOGIA
}

\author{
Dulce Márcia Cruz \\ Klalter Bez. Fontana \\ Lidnei Ventura
}

Resumo

O artigo está baseado em uma pesquisa exploratória desenvolvida no $4^{\circ}$ e $5^{\circ}$ semestre do curso de Pedagogia a Distância da UDESC. A investigação teve como objetivo problematizar como as mídias aparecem no contexto da educação infantil, qual a percepção dos acadêmicos sobre elas e quais as possibilidades de uso nesse contexto. Para compreensão do fenômeno, lançou-se mão de dois instrumentos de coleta de dados: Roteiro de Observação e Projeto de Intervenção Docente. Os resultados apontam que as mídias ainda são vistas e utilizadas como recursos didáticos, mas não alinhadas à perspectiva da mídia-educação, tornando essencial o debate sobre tais questões no processo formativo docente, em especial, na formação inicial de educadores.

Palavras-chave: educação a distância; mídias; educação infantil.

\section{THE MEDIA IN THE DAILY OF CHILD EDUCATION ON THE PEDAGOGY ACADEMICS PERSPECTIVE}

\begin{abstract}
The article is based on an exploratory research developed in the 4th and 5th semester of the UDESC Distance Pedagogy course. The research aimed to discuss how the media appear in the context of early childhood education, what is the perception of academics about them and what the possibilities of use in this context. To understand the phenomenon, two data collection instruments were used: observation script and Teaching Intervention Project. The results indicate that the media are still seen and used as didactic resources, but not aligned with the perspective of the media education, making the debate about such issues essential in the educational formative process, especially in the initial formation of educators.
\end{abstract}

Keywords: distance education; media; child education.

\section{LOS MEDIOS DE COMUNICACIÓN EN LO COTIDIANO DE LA EDUCACIÓN INFANTIL EN LA PERSPECTIVA DE LOS ACADÉMICOS DE PEDAGOGIA}

Resumen

El artículo se basa en una investigación exploratoria desarrollada en el cuarto y quinto semestre del curso de Pedagogía a Distancia de la UDESC. La investigación tuvo como objetivo discutir cómo aparecen los medios en el contexto de la educación de la primera infancia, cuál es la percepción de los académicos sobre ellos y cuáles son las posibilidades de uso en este contexto. Para comprender el fenómeno, se utilizaron dos instrumentos de recolección de datos: ruta de observación y Proyecto de intervención docente. Los resultados indican que los medios aún se ven y utilizan como recursos didácticos, pero no están alineados con la perspectiva de la educación en medios, lo que hace que el debate sobre estos temas sea esencial en el proceso formativo del profesorado, especialmente en la formación inicial de educadores.

Palabras-clave: educación a distancia; medios de comunicación; educación infantil. 


\section{INTRODUÇÃO}

Uma das características marcantes da modernidade é a emergência de processos massificados de informação e comunicação, os mass media.

As condições de reprodutibilidade adquiridas pelos bens culturais e artefatos artísticos ainda no final do século XIX, tais como estudadas por Walter Benjamin (2015) em um de seus famosos ensaios, A obra de arte na era de sua reprodutibilidade técnica, apontam para a reflexão levantada por importantes autores contemporâneos: toda sociedade cria sua própria mídia enquanto expressão das relações sociais do seu tempo (THOMPSON, 1998; GIDDENS, 2002).

A questão da mídia suscitou, desde os anos 20 do século XX, reflexões seminais sobre o seu influente papel no contexto da emergente urbanização do Meio Oeste americano, principalmente na cidade de Chicago, tornando-a objeto de estudo dos pioneiros em Sociologia Urbana da chamada Escola de Chicago. Quase em paralelo a Chicago, os estudos da Escola de Frankfurt apontaram para os efeitos perniciosos da mídia na sociedade urbana, cunhando o conceito de indústria cultural, abrindo um amplo leque de perspectivas para o estudo da mídia.

Atualmente, tanto as discussões do campo educacional quanto a sua previsão em documentos legais exigem dos educadores uma profunda reflexão sobre o uso de mídias em processos de ensino e aprendizagem desde a educação infantil. Documentos internacionais e nacionais voltados à educação contemplam essa questão, como é o caso do Marco de Avaliação Global da Alfabetização Midiática e Informacional (AMI), da UNESCO (2016), Diretrizes Curriculares Nacionais para a Educação Infantil (2010) e, mais recentemente, a Base Nacional Comum Curricular (2017).

Em que pese essas orientações, o trabalho pedagógico com a mídia na educação infantil ainda se revela frágil e dependente do uso de equipamentos audiovisuais, reduzindo o conceito a um de seus aspectos, ocultando um complexo sistema que envolve tanto os meios de comunicação e produção cultural (mediações) quanto os próprios aparelhos e dispositivos tecnológicos (meios) usados no processo comunicativo e suas linguagens e a um complexo sistema de relações e poder (VENTURA, 2018).

Assim, considerando o importante papel desempenhado pela mídia enquanto instituição e sua centralidade para a experiência moderna e contemporânea (SILVERSTONE, 2002), há que se considerar que o processo de formação de educadores não pode passar ao largo dessa relevante temática. Pelo contrário, é crucial que as instituições que lidam com a formação de educadores contemplem o que Belloni (2018) chamou de formação para mídia-educação, a fim de que seus egressos compreendam as influências das mídias no contexto atual e seus desdobramentos para as práticas pedagógicas, formando "[...] cidadãos capazes de serem usuários competentes, críticos, criativos e participativos, a começar pela sua própria formação" (BELLONI, 2018, p. 450).

A partir dessa problemática e a fim de contribuir com o processo formativo de pedagogos, o presente artigo descreve uma pesquisa exploratória desenvolvida concomitantemente nas disciplinas de Seminário Integrador IV: Educação, Infância e Tecnologias, Seminário Integrador V: Planejamento e Avaliação na Educação Infantil e Estágio Curricular Supervisionado I e II, respectivamente no $4^{\circ}$ e $5^{\circ}$ semestre do curso de Pedagogia a Distância da UDESC [2019.1 e 2019.2]. A investigação teve como objetivo identificar e analisar como os acadêmicos observaram a presença e uso de mídias no cotidiano da educação infantil em dois momentos distintos do processo de estágio: leitura de contexto e intervenção docente. O processo de pesquisa e as atividades propostas aos acadêmicos tiveram por finalidade problematizar como as mídias 
DOI: https://doi.org/10.12957/teias.2020.48632

aparecem no contexto da educação infantil, qual a percepção dos acadêmicos sobre elas e quais as suas possibilidades de utilização em processos de ensino e aprendizagem.

Levando em conta que há poucos estudos específicos sobre acadêmicos da educação a distância (VENTURA, 2018), sobretudo em processo de estágio, o presente estudo levanta parte do itinerário formativo de um grupo de acadêmicas que, em cidades diferentes do estado de Santa Catarina, foram instadas a lançar um olhar reflexivo e sensível sobre a presença e o uso de mídias no contexto da educação infantil no período de observação participante e intervenção docente no estágio curricular supervisionado.

\section{BREVES NOTAS SOBRE MÍDIAS E MÍDIA-EDUCAÇÃO}

Por sua função estratégica no contexto social moderno, e sua onipresença no contexto contemporâneo (SILVERSTONE, 2002), estudos de mídia têm se revelado cruciais para a compreensão de um estilo de vida cada dia mais mediado digitalmente. Conforme Giddens (2002) e Thompson (1998), o surgimento da mídia se constitui como uma experiência articulada à própria modernidade, sendo seus impactos difíceis de dimensionar, dado o seu caráter de compressão espaço-temporal, na medida em que favorecem o alargamento territorial, ao passo que comprimem o tempo de veiculação de informações.

No estudo da relação entre mídia e modernidade, Thompson (1998) destacou a característica da reprodutibilidade das formas simbólicas, produzidas e reproduzidas pelas indústrias da mídia e que atingem em cheio o sujeito comum através de um mecanismo multimidiático, apontando para “[...] o fato de que a recepção dos produtos da mídia é uma rotina, uma atividade prática que muitos indivíduos já integram como parte de suas vidas cotidianas" (THOMPSON, 1998, p. 41). Na mesma linha de pensamento, Giddens (2002, p. 29-32) reitera os impactos sociais da mídia na modernidade, dizendo que:

[...] na medida em que um meio serve para alterar as relações espaço-temporais, não depende fundamentalmente do conteúdo ou das "mensagens" que carrega, mas de sua forma ou reprodutibilidade, e acrescenta: Em suma, nas condições da modernidade, os meios de comunicação não espelham realidades, mas em parte as formam.

Para os autores, está claro que mídia e modernidade são inseparáveis, pois, a modernidade se instaura sob o signo da revolução tecnológica, a cada dia de modo mais radical e sofisticado, ampliando os tipos e capacidades dos sistemas especializados.

Outro aspecto relevante do estudo de Thompson (1998) é a implicação da mídia em relações de poder, caracterizando-a como um poder altamente relevante, a ponto de o autor considerá-la com o quarto poder, poder cultural ou simbólico, interagindo e concorrendo com o poder econômico, político e coercitivo.

Considerando, então, as relações simbióticas de constituição entre mídia e sociedade, a educação não poderia ignorar a sua presença nos espaços educativos. De modo que não se pode conceber a educação atual sem considerar a mídia como um dos seus elementos constituintes. Assim, mídia e educação estão sujeitas a implicações mútuas, a ponto de autores renomados neste campo criarem o neologismo mídia-educação ou media education (BUCKINGHAM, 2010). Embora esse termo venha mudando desde digital literacy (Comissão Europeia), media and information literacy (UNESCO) (BELLONI, 2018), no Brasil, o termo composto mídia-educação vem ganhando cada 
DOI: https://doi.org/10.12957/teias.2020.48632

vez mais projeção e se estabilizando como uma importante área de pesquisa e formação de educadores. Para Belloni (2009, p. 1083) as pesquisas em mídia-educação se tornam essenciais “[...] para os processos de socialização das novas gerações, mas não apenas, pois deve incluir também populações adultas, numa concepção de educação ao longo da vida".

$\mathrm{Na}$ contemporaneidade, não se pode negar a presença das mídias em nosso cotidiano, e em especial, sua presença determinante na vida das crianças. Conforme destaca Buckingham (2007, p. 65), "[...] longe de serem vítimas passivas das mídias, as crianças passam a ser vistas como dotadas de uma forma poderosa de 'alfabetização midiática', uma sabedoria natural espontânea de certo modo negado aos adultos". Ou seja, as crianças por já nascerem numa cultura fortemente marcada pelo digital, pela presença das mídias em seu cotidiano, passariam a ter uma relação que de certa forma naturaliza essas práticas, enquanto para o adulto ainda causaria um estranhamento e a necessidade de desenvolvimento de determinadas habilidades para inserção nessa cultura midiatizada.

Dessa forma, não há como negar a importância das mídias no contexto educacional sistematizado. Como artefatos culturais que estão presentes no cotidiano das crianças, muitas pesquisas já vêm destacando "[...] a importância crescente das mídias na criação dos 'mundos sociais e culturais das crianças', onde ocorrem os processos de socialização” (GOMES; BELLONI, 2008, p. 722).

E quando falamos em educação para as mídias, torna-se imprescindível discutir também sobre a importância desse debate na formação dos professores. Assim, a relação mídia-educação aparece em suas duas dimensões que são inseparáveis: "[...] objeto de estudo e ferramenta pedagógica, ou seja, como educação para as mídias, com as mídias, sobre as mídias e pelas mídias" (BELLONI, 2009, p. 1084). Pois, somente assim, será possível à escola oferecer condições para que as crianças e jovens se apropriem crítica e criativamente dos recursos midiáticos, usando-os, como acrescenta a autora acima, "[...] como meios de participação e expressão de suas próprias opiniões, saberes e criatividade".

Assim, não basta somente falar sobre as mídias, mas é essencial que os professores em formação compreendam o significado do que sejam mídias, não apenas como meros recursos didáticos, mas também como artefatos culturais, reconhecendo a importância da inserção desses recursos nos processos educativos também como fontes diferentes de pesquisa e de compreensão e expressão de ideias, criatividades e invenções.

Para o pedagogo em formação, sobretudo nos momentos de estágio, quando se aproxima mais do campo profissional de atuação, propor a discussão sobre mídia-educação é fundamental. Primeiramente, pela constatação da presença massiva da mídia nas relações sociais contemporâneas, mas também por conta das orientações presentes nos marcos legais da educação, cujos documentos apontam para contemplação, tanto no currículo da formação de professores quanto no exercício profissional dos habilitados ao exercício profissional nas primeiras etapas da educação básica, dos quais destacamos as Diretrizes para a Educação Infantil- DCNEI [Resolução CNN n. 05/2009] e a Base Nacional Curricular Comum - BNCC [Resolução CNE/CP n. 02/17]. Nas DCNEI, o trabalho com as mídias aparece como um dos objetivos inerentes aos eixos curriculares fundamentais da educação infantil: educar e brincar (BRASIL, 2009). Já resolução que institui a BNCC, o artigo $4^{\circ}$ prevê o desenvolvimento das seguintes competências:

5. Compreender, utilizar e criar tecnologias digitais de informação e comunicação, de forma crítica, significativa, reflexiva e ética nas diversas práticas sociais (incluindo as escolares) para se comunicar, acessar e disseminar 
DOI: https://doi.org/10.12957/teias.2020.48632

informações, produzir conhecimentos, resolver problemas e exercer protagonismo e autoria na vida pessoal e coletiva (BRASIL, 2017).

Como se pode ver, a educação com e para as mídias está presente enquanto diretriz para o trabalho com as crianças, o que implica diretamente sua previsão na formação dos profissionais da educação. E foi para contemplar esse aspecto importante da formação no curso de Pedagogia, na modalidade a distância, que desenvolvemos a pesquisa que passamos a relatar.

\section{ASPECTOS METODOLÓGICOS E ANÁLISE DA PESQUISA SOBRE A PRESENÇA DAS MÍDIAS NA EDUCAÇÃO INFANTIL}

Como assinala Belloni (2018, p. 450), “[...] a mídia-educação deve ser considerada também na formação de professores, um método inovador que propõe formas novas de ensinar e aprender, com novos artefatos técnicos". Assim, nada mais oportuno do que o período de estágio curricular supervisionado, quando o acadêmico se aproxima de forma mais intensa e prática do seu futuro campo profissional, para levantar questões e problematizar o uso pedagógico da mídia e contribuir com sua formação docente, colaborando para a construção de um profissional que apreenda sensível e criticamente a implicação da presença das mídias no universo infantil contemporâneo.

Deste modo, o objetivo dessa pesquisa qualitativa, de cunho exploratório, foi identificar e analisar como os acadêmicos observaram a presença e uso de mídias no cotidiano da educação infantil em dois momentos distintos do processo de estágio: leitura de contexto e intervenção docente. Assim, a pesquisa teve dois momentos de coleta dos dados: a observação do uso de mídias na educação infantil [leitura de contexto] e uso de mídias no processo de intervenção docente.

A presente pesquisa iniciou no primeiro semestre de 2019, tendo como sujeitos principais os acadêmicos da $4^{\mathrm{a}}$ fase do curso de Pedagogia a distância da UDESC. Este curso recebe fomento da Universidade Aberta do Brasil (UAB) e contempla três turmas, localizadas nos municípios de Jaraguá do Sul, Balneário Piçarras e Quilombo, com um total de 73 acadêmicos inscritos. Esses municípios estão dispostos geograficamente em regiões diferentes do estado de Santa Catarina: sendo Jaraguá do Sul pertencente à microrregião de Joinville, Balneário Piçarras localizado no litoral norte e, Quilombo, localizado no extremo oeste do estado.

Como se sabe, diferenças regionais influenciam diretamente no processo de formação dos sujeitos, pois o consumo e uso de mídias está diretamente ligado às práticas socioculturais realizadas no cotidiano de cada comunidade. Sendo assim, era intenção da pesquisa considerar essa variável na análise dos resultados.

É importante salientar que os acadêmicos do curso têm o primeiro contato sistematizado com o campo profissional da educação infantil na $4^{a}$ fase, quando realizam a leitura de contexto por meio da observação participante. Em todas as fases do curso, o projeto pedagógico prevê uma disciplina, cuja função é propor a integração interdisciplinar em cada fase, chamada Seminário Integrador. No caso da $4^{\mathrm{a}}$ fase, quando iniciou essa pesquisa, o estágio ocorreu junto ao Seminário Integrador IV: Educação, Infância e Tecnologias.

Nesse primeiro contato com o estágio, os acadêmicos foram a campo realizar a leitura de contexto das instituições de educação infantil, como forma de levantarem previamente elementos para a prática docente que iria ocorrer no semestre seguinte. Assim, essa leitura de contexto serviria como uma forma de reconhecer esse espaço educacional e fazer um diagnóstico dos aspectos que poderiam ser contemplados na elaboração do projeto de docência. Diante desse contexto, e do propósito da disciplina de seminário, nada mais oportuno do que aproveitar a ida desses 
acadêmicos à campo para incluir nessa leitura de contexto elementos em que pudéssemos perceber o olhar desses acadêmicos para as mídias e sua presença na educação infantil.

No segundo momento, os acadêmicos levantaram problemáticas referentes ao contexto das instituições de educação infantil de suas regiões e, juntamente com os profissionais do campo de estágio, elaboraram seus projetos de intervenção docente. A proposta de estágio prevê 54 horas de intervenção, estruturadas a partir de sequências didáticas previamente aprovadas pelos supervisores de estágio.

A pesquisa se desenvolveu nesses dois momentos do estágio, que passamos a descrever.

\section{A pesquisa e os procedimentos}

\section{$1^{\circ}$ Momento:}

Esse momento da pesquisa partiu da análise de dados qualitativos colhidos pelos acadêmicos durante a leitura de contexto no campo de estágio da educação infantil. $O$ caminho metodológico escolhido foi o levantamento de dados a partir de um roteiro estruturado, que pudesse nortear os acadêmicos acerca dos aspectos a serem observados. O roteiro continha questões norteadoras de pesquisa na perspectiva de geração de dados (BAUER; GASKELL, 2012) e não como questionário fechado.

O objetivo foi ampliar a mirada investigativa dos acadêmicos, estimulando suas percepções e aproveitando as discussões e problematizações encampadas pelo Seminário Integrador sobre a presença da mídia na sociedade contemporânea, os autores que a pesquisam, bem como sua presença no universo infantil.

Partiu-se, então, da perspectiva de que investigar uma realidade social não se resume à aplicação de instrumentos de pesquisa, mas requer a observação sistemática e atenta de todos os elementos presentes naquele contexto (BAUER; GASKELL, 2012). Em função disso, optou-se por uma pesquisa qualitativa do tipo exploratória, cujo objetivo é "[...] proporcionar visão geral, de tipo aproximativo, sobre determinado fato", mas cujo "[...] produto final deste processo passa a ser um problema mais esclarecido, passível de investigação mediante procedimentos mais sistematizados" (GIL, 2008, p. 27). Longe, então, de esgotar o assunto, a pesquisa teve por finalidade, nos dois momentos, levantar questões, proporcionar reflexões e lançar novas perguntas sobre o uso de mídias na educação infantil.

Os alicerces teóricos oferecidos aos acadêmicos antes da ida a campo partiram de problematizações acerca do conceito de infância, o uso e a presença das mídias em nosso cotidiano, bem como a influência dos recursos midiáticos no desenvolvimento infantil nas práticas sociais atuais. Esse debate, realizado por meio de encontro presencial e no Ambiente Virtual de Aprendizagem (AVA), serviu como uma preparação para que o olhar desses sujeitos em formação tivesse sua lente ajustada para a percepção das mídias e sua presença na educação infantil. Como nos diz Belloni (2009), é preciso que o educador tenha um olhar global sobre as mídias, vendo-a por todos os seus vieses (para, com, sobre e através das mídias), como um caleidoscópio, que mostra diferentes nuances sobre um fato ou objeto. Foram estudados autores como David Buckingham, Mônica Fantin e Gilka Girardello, que foram as bibliografias básicas da disciplina, tendo-se outros autores que debatem o tema da mídia-educação como bibliografias suplementares. Com isso, construiu-se uma importante bibliografia para subsidiar a discussão proposta, bem como proporcionar ferramentas conceituais para a ida desses grupos a campo no momento de observação da presença das mídias no contexto das instituições de educação infantil nos municípios. Desta 
DOI: https://doi.org/10.12957/teias.2020.48632

forma, integrou-se o Seminário IV ao Estágio Curricular para fundamentar olhares múltiplos a respeito da temática proposta.

O roteiro foi elaborado com cinco questões norteadoras de pesquisa, contemplando três eixos de análise: presença, utilização e consumo dos recursos midiáticos no espaço da educação infantil. Durante os dois meses em que estiveram no campo de estágio, os acadêmicos realizaram essa incursão em campo a partir das formações de grupos permitidos pelo regulamento de estágio: individualmente, dupla ou trio. O resultado da investigação foi apresentado no gênero de texto acadêmico, contemplando o contexto observado e os elementos propostos nas cinco questões orientadoras.

A tabela abaixo descreve a amostragem desse primeiro momento de pesquisa:

Tabela 1: Participantes na pesquisa por município

\begin{tabular}{|c|c|l|l|l|l|}
\hline $\begin{array}{l}\text { Total de } \\
\text { matrículas }\end{array}$ & $\begin{array}{l}\text { Total de } \\
\text { participantes }\end{array}$ & $\begin{array}{l}\text { Trabalhos } \\
\text { apresentados }\end{array}$ & $\begin{array}{l}\text { Participantes } \\
\text { por cidade }\end{array}$ & Cidade & $\begin{array}{l}\text { Instituições } \\
\text { (CEIM) }\end{array}$ \\
\hline 76 & 66 & 29 & 17 & Balneário Piçarras & 17 \\
\cline { 3 - 4 } & & & 12 & Quilombo & \\
\hline
\end{tabular}

Fonte: elaborada pelos autores, 2019.

Além de ser uma relevante pesquisa exploratória, essa atividade teve como objetivo despertar nos acadêmicos o espírito investigativo, de acordo com as perspectivas apontadas por Freire (1997, p. 29), pois não há ensino sem pesquisa e pesquisa sem ensino e por Demo (2006, p. 02), quando afirma que educar pela pesquisa "[...] tem como condição essencial primeira que o profissional da educação seja um pesquisador, ou seja, maneje a pesquisa como princípio científico e educativo e a tenha como atitude cotidiana". Partindo desses princípios, a investigação continuou no semestre seguinte.

$2^{\circ}$ Momento

Esse momento teve como instrumento de geração de dados os projetos de intervenção docente elaborados pelos acadêmicos a partir das problemáticas levantadas na leitura de contexto. Os acadêmicos elaboraram seus projetos de docência a partir da metodologia da Sequência Didática, organizados por Momentos de Aprendizagem.

Foram analisados 29 projetos de intervenção docente, mantendo-se o alinhamento com os dados apresentados na Tabela 1, pois se tratou de uma continuidade do Estágio Curricular Supervisionado I.

Tabela 2: Projetos de intervenção por município

\begin{tabular}{|c|c|l|c|l|l|}
\hline $\begin{array}{l}\text { Total de } \\
\text { matrículas }\end{array}$ & $\begin{array}{l}\text { Total de } \\
\text { participantes }\end{array}$ & $\begin{array}{l}\text { Projetos } \\
\text { apresentados }\end{array}$ & $\begin{array}{l}\text { Projetos por } \\
\text { cidade }\end{array}$ & Cidade & $\begin{array}{l}\text { Instituições } \\
\text { (CEIM) }\end{array}$ \\
\hline 76 & 66 & 29 & 09 & Balneário Piçarras & 17 \\
& & & 06 & $\begin{array}{l}\text { Quilombo } \\
\text { Jaraguá do Sul }\end{array}$ & \\
\hline
\end{tabular}

Fonte: elaborada pelos autores, 2019.

Dos 29 projetos analisados, apenas oito trouxeram como temática principal o uso de mídias no contexto da educação infantil, sendo que em todos estes o recorte foi para o uso de alguma 
literatura infantil como carro chefe do projeto. Entretanto, quando se volta o olhar para as sequências didáticas elaboradas, percebe-se que em todas elas o uso de mídias é contemplado, sendo o recorte midiático restrito a filmes, músicas e literaturas do universo infantil. Assim, como fonte de dados, todos os projetos de intervenção docente foram analisados para o presente trabalho.

Com base no conjunto dos dados coletados no primeiro e segundo momento de pesquisa é que foi permitido traçar algumas aproximações sobre a questão da presença das mídias nas instituições campo de estágio pesquisadas, assim como a presença/ausência delas nos projetos de intervenção docente, conforme segue no próximo item.

\section{Imagens e vozes sobre a presença/ausência das mídias nos espaços da educação infantil}

O procedimento adotado para a análise dos dados levantados pela pesquisa teve por base o roteiro elaborado para orientação da observação participante [ $^{\circ}$ momento]. Como já mencionado, foram propostas cinco questões abertas que no seu conjunto informaram sobre aspectos indicativos da presença/ausência das mídias no universo investigado. A primeira se referia ao contexto histórico-social daquela instituição a fim de informar sobre os condicionantes das práticas sociais de uso de mídias. As outras quatro questões estavam voltadas mais diretamente para as mídias: presença, ausência, uso e consumo, além de se considerar o uso de mídias numa perspectiva inclusiva. Importante ressaltar que o objetivo não foi avaliar a prática educacional observada, mas se os acadêmicos conseguiram apreender a importância da presença da mídia no cotidiano da educação infantil, não somente como recurso, mas como artefato cultural e sua característica de reprodutibilidade das formas simbólicas, como destacado por Thompson (1998). Seguindo as questões propostas, inferimos as reflexões que seguem.

\section{Presença das mídias}

A fim de orientar as primeiras aproximações com o campo de estágio e observar a presença das mídias no contexto da educação infantil, esse primeiro questionamento foi desdobrado nas seguintes questões: quais mídias estão presentes e em quais espaços estão disponibilizadas? O projeto da escola e o planejamento docente mencionam e/ou orientam sobre a utilização das mídias no processo educacional? As mídias estão inseridas no planejamento das ações de aprendizagem? Existe suporte técnico aos professores? Os mesmos receberam formação sobre o uso das mídias na educação infantil e/ou isso está previsto no PPP?

Com relação à consideração da mídia enquanto equipamento ou artefato, os acadêmicos observaram a presença da televisão, do DVD e do aparelho de som nas salas de aula. Apareceram poucos relatos de escolas com laboratórios de informática em todas as regiões pesquisadas e, quando estes eram mencionados, destacaram a ausência do técnico para suporte no uso da sala e que, mesmo existindo em casos isolados, alguns estavam fechados. Informaram, ainda, que a televisão, DVD e rádio tinham presença mais frequente na primeira etapa da educação infantil (berçário), enquanto que, com as crianças maiores, perceberam a presença também do computador e da máquina fotográfica em sala, embora não tenham informado sobre o seu uso no cotidiano docente.

Notaram também que o Datashow é um recurso presente, embora fique na biblioteca. Computadores e impressoras também foram notados nas secretarias escolares. Não observaram a presença de celulares para fins pedagógicos, nem mencionaram a presença de revistas, jornais, 
DOI: https://doi.org/10.12957/teias.2020.48632

livros e outros recursos característicos da mídia impressa, embora se saiba que tais recursos normalmente estão disponíveis nas salas de aula da educação infantil. Aqui talvez se possa inferir que esses recursos ainda não são percebidos como elementos midiáticos, o que aponta a necessidade de percepção das mídias enquanto um verdadeiro sistema de informação, além de ser "[...] instrumento, linguagem, espaço de negociação e de conteúdos, distribuição de bens culturais" (CRUZ; VENTURA, 2018, p. 444) e espaço de mediação simbólica e de constituição de identidades. Esse dado aponta para uma certa conformação e redução do conceito de mídia aos seus aspectos exteriores, o que não favorece a construção de uma formação para educação midiática. Chama ainda atenção que a presença das mídias, mesmo consideradas como recursos técnicos e artefatos, era tão insignificante que nem se fizeram notar pelos observadores. Essa constatação lembra a consideração de Silverstone (2002) de que o sujeito moderno vive imerso em relações cada vez mais mediadas por processos multimidiáticos. Devido a tal centralidade, cabe àqueles que lidam com a formação de educadores maior foco em programas e processos de educação para as mídias. Sobre essa questão, Buckingham aponta para o fato de que o trabalho com as mídias pode partir de algo simples, sobretudo por estarem presentes no cotidiano das crianças. Sobre isso, diz o autor:

O que eu diria é que se pode fazer educação para as mídias com tecnologia simples, não se precisa de muita coisa. Pode-se fazer um trabalho muito bom com papel, tesoura e cola. Fotografia também, apesar de também ser cara. Colagens, criação de imagens, acho que podem render bastante. Trabalhos com revistas velhas, jornais, em que você literalmente desconstrói coisas. Com esses materiais as crianças podem fazer muita coisa criativa e também crítica. Outra coisa importante são os exercícios com teatro e performance, já que boa parte do que se vê na televisão é basicamente teatro. (BUCKINGHAM, 2015)

Essa passagem desmistifica a ideia de que o trabalho com as mídias deve se resumir aos meios eletrônicos ou atividades espetaculares, mas sim partir de iniciativas simples. Essa questão alerta para a necessidade de um trabalho que leve à formação de "[...] cidadãos capazes de serem usuários competentes, críticos, criativos e participativos, a começar pela sua própria formação" (BELLONI, 2018, p. 450).

Essa necessidade formativa apareceu também nos projetos de intervenção, pois poucas sequências didáticas trouxeram as mídias ou estudo de mídia para a prática pedagógica do estágio. Em sua grande maioria, os projetos exploraram recursos midiáticos já comumente utilizados no universo da educação infantil, tais como vídeos, aparelhos de som e livros de literatura. Como nessa etapa formativa o registro docente é algo essencial à prática, tanto como forma de acompanhar o aprendizado das crianças quanto como ferramenta para avaliar sua própria atuação, os acadêmicos fizeram uso de celulares para esta finalidade, e não como uma mídia que pode ser explorada pedagogicamente com as crianças em atividade de ensino-aprendizagem.

\section{O uso das mídias no processo pedagógico}

Nessa questão, os acadêmicos foram orientados a observar os elementos presentes na prática de utilização das mídias. Os desdobramentos dessa questão norteadora foram: verificou-se o uso das mídias no processo educacional com as crianças? Caso sim, como pode se avaliar essa utilização? Quais mídias mais utilizadas? $O$ uso é de caráter recreativo ou existe uma intencionalidade pedagógica? $\mathrm{O}$ uso das mídias considera a faixa etária das crianças? Quem 
DOI: https://doi.org/10.12957/teias.2020.48632

manuseia as mídias utilizadas? Que tipos de interações elas proporcionaram nas práticas observadas?

A maioria dos relatos da observação dão conta de que as mídias presentes na escola são de uso majoritariamente recreativo, para entreter e nem sempre integrada a uma intencionalidade pedagógica, especialmente o uso da televisão, tal como demonstrado nos estudos de Siqueira, Wiggers e Souza (2012). Por se tratarem de práticas culturais complexas, houve variantes nas situações observadas em que foi percebida intenção no uso da mídia, como a exemplo do celular, que o professor usou na função lanterna (jogo de sombras) e fotografia (para trabalhar o auto reconhecimento das crianças). Outra situação foi a observada e relatada abaixo por um grupo de estagiários:

No caso das aulas de Arte, a professora disponibiliza, entre outras, às crianças revistas para manuseio e colagem; a professora de sala utiliza áudio para que as crianças articulem suas falas através de cantos e contação de histórias regionais, entre outras práticas (ACADÊMICOS GRUPO 10).

Mesmo se considerando esses casos excepcionais, o uso da TV e da música ainda carecem de planejamento numa proposta voltada para a mídia-educação. Como foi evidenciado anteriormente, as mídias televisão, DVD e aparelho de música ainda são as mais comuns na educação infantil, em especial no berçário e na creche. A constatação do uso de tais recursos se mostrou predominante, como exemplificado no relato abaixo que, de certa forma, evidencia o olhar presente na maioria das observações, mesmo em se tratando de diferentes contextos observados:

Para nós, o uso da televisão, especialmente na hora dos vídeos não estava associado a intencionalidade pedagógica porque, sem nenhuma introdução ou objetivo pedagógico, ela os conduzia a sentar para assistir o que ela definia, nestes momentos, portanto, não presenciamos interação da professora com as crianças no sentido de saber o que gostariam de assistir (ACADÊMICOS GRUPO 1).

Entretanto, foi muito importante notar que a discussão em torno da mídia, sua presença ou ausência nos campos de estágio favoreceu a configuração do olhar dos acadêmicos para essa questão, pois se conseguiram perceber a falta de intencionalidade pedagógica da proposta de uso da televisão no episódio relatado, é porque as problematizações desenvolvidas nas disciplinas do semestre de alguma forma colimaram em processos de educação para a mídia.

Outro aspecto observado em sala pelos acadêmicos foi que os equipamentos audiovisuais são utilizados basicamente pelas auxiliares entre uma rotina de cuidado e outra, repetindo o uso da TV com vídeos e músicas restrito a passatempos. Contrapondo essa prática, o relato a seguir denota a necessidade de adotarmos uma forma de ver o uso de mídias numa perspectiva mais promissora e pedagogicamente comprometida:

Esta situação poderia se mostrar diferente se os recursos fossem utilizados de forma conjunta com o intuito pedagógico, aliando um desenho ou alguma música como ferramentas que ajudam a construir algum diálogo ou participação em alguma atividade. O que vimos era apenas uma forma de controle, usada o tempo todo sem pausas e de maneira avessa ao processo educacional (ACADÊMICOS GRUPO 2).

Os recursos informatizados se mostraram presentes nas escolas observadas, em especial em laboratórios de informática, salas de secretaria e coordenação e sala de aula. Mas, é notória a 
observação de que tais recursos ficam de uso exclusivo do professor, nem sempre para uso pedagógico, como exemplifica o seguinte relato:

Não percebemos a utilização de computadores pelas crianças sendo que existe uma sala de informática que poderia ser utilizada, e propor dessa forma aos alunos atividades e jogos interativos, diversificados e lúdicos, auxiliando na aprendizagem (ACADEMICOS GRUPO 3).

Os acadêmicos informaram ainda que em conversa com os professores das turmas observadas, foi comum a fala de que querem usar os recursos midiáticos com as crianças, mas que não se sentem preparados para inserir os recursos no seu planejamento, em especial com crianças pequenas de creche e berçário. Assim, pode-se inferir que, embora os projetos pedagógicos apontem para a necessidade e importância das mídias na escola, nem sempre esse discurso se traduz em práticas efetivas no cotidiano da educação infantil, situação essa que abre um campo importante de formação continuada em mídia-educação para educadores partindo de sua própria práxis educativa.

Durante o período de intervenção docente [ $2^{\circ}$ Momento], todos os 29 projetos foram avaliados. Destes, somente oito trouxeram a mídia como temática principal de suas sequências didáticas, sendo aqui a mídia restrita a livros de literatura infantil. No entanto, em todas elas a música, os filmes e os livros foram contemplados. De todos os projetos, somente um contemplou o uso de projetor de slides e dois contemplaram mídia impressa, como revista. Mas, é importante ressaltar que em todas as sequências a mídia foi usada apenas recurso didático, não estando esse uso vinculado a uma concepção de mídia-educação, conforme discutido nas notas sobre mídia e mídia-educação do presente trabalho.

\section{O uso das mídias numa perspectiva inclusiva}

No âmbito dos estudos realizados nas disciplinas nos dois semestres de 2019, essa questão revelou-se problemática e desafiadora em vários aspectos. Um dos que mais chama a atenção são os desafios postos às tecnologias assistivas, pois esse é um debate que mal se instalou na academia e sequer chegou às instituições de educação, principalmente na educação infantil. Estudos de Böck (2019) deixam claro que as pesquisas e discussões em torno de um Desenho Universal para a Aprendizagem (DUA) são inexpressivos no Brasil, o que tende a entravar o processo de inclusão de todos os sujeitos no ambiente educativo.

Considerando essa problemática, o intuito foi instrumentalizar teoricamente nossos acadêmicos a perceber elementos voltados à criança especial, mesmo que isso redundasse numa perspectiva de inclusão insatisfatória e que considera a especificidade dos casos e não a inclusão de todos em processo de aprendizagem. Mesmo considerando essa limitação, alguns nortes para observação foram sugeridos: observar as propostas, a autonomia e a independência direcionada à criança público da educação especial no desenvolvimento das atividades com mídias.

Nos relatos apresentados, os acadêmicos em geral não fizeram uma análise específica sobre o uso das mídias com crianças com necessidades especiais. Nas turmas observadas, que tinham crianças especiais, o olhar dos acadêmicos se deteve sobre o processo pedagógico de inclusão como um todo, não se atendo especificamente sobre o uso das mídias na perspectiva inclusiva. Quando essa análise mais apurada foi feita, incidiu no uso da televisão, vista aqui como uma mídia disponível, mas nem sempre inclusiva. Em geral, como podemos observar nos relatos abaixo, ainda há um distanciamento entre a prática pedagógica inclusiva e o uso de mídias. Vejamos um exemplo: 
Caso tivessem alguma criança especial na escola observamos que existem propostas, a autonomia e a independência direcionada a criança, público da educação especial, no desenvolvimento das atividades, mas não com mídias. Pois as atividades são realizadas com todas as crianças e é usado o mesmo material, não tem adaptações e muito menos se faz uso de mídia assistiva, por não terem atendido nenhum caso ainda (ACADÊMICOS GRUPO 4).

O que se repetiu no seguinte caso: "A docente disse que faz uso de vídeos educativos e filmes com todos da turma e não passa nenhum em específico para o garoto". (ACADÊMICOS GRUPO 3)

Da mesma forma que para o uso das mídias em geral, os alunos perceberam a necessidade de os professores serem preparados para receber uma criança com deficiência, incluindo o trabalho com mídias. É o que indica a fala abaixo:

Ao perguntar a professora do Pré I C sobre sua formação e se estaria preparada para receber uma criança de inclusão, ela nos foi bem sincera dizendo que não. Mesmo a creche promovendo acessibilidade interna estrutural, a maioria das profissionais não se sente preparada e vive angustiada só de pensar em receber uma criança especial. (ACADEMICOS GRUPO 5).

Surge daí uma nova demanda para os cursos de formação inicial e continuada de professores, pois além da capacitação envolver o trabalho com as mídias, é preciso contemplar no currículo as relações entre mídias e educação inclusiva, destacando-se a formação para a criação e uso de tecnologias assistivas e proposições voltadas ao desenho universal.

\section{Práticas de consumo das mídias}

Esse eixo de observação tinha como intenção a percepção da presença das mídias comerciais no contexto das instituições de educação infantil. A observação esteve pautada nas seguintes questões: Quais elementos da mídia comercial estão presentes nos espaços observados? Nas brincadeiras, nos jogos utilizados, quais referências utilizadas? E nos produtos de consumo: mochilas, tênis, roupas?

Nos relatos apresentados pelos acadêmicos, nota-se a forte influência dos personagens e programas midiáticos no comportamento das crianças, seja influenciando suas brincadeiras e rodas de conversas, seja na presença dos personagens em roupas e acessórios. Mesmo considerando o fato de que as três cidades da pesquisa têm realidades econômicas diferenciadas, os relatos do consumo das mídias mostraram de forma semelhante o quanto a linguagem midiática, enquanto poder cultural ou simbólico (THOMPSON, 1998) exercem um apelo comercial bastante forte, influenciando em comportamentos e linguagens. Conforme assinala Giddens (2002), nessas situações a mídia não somente espelha realidades, mas em boa parte as formam. Exemplo disso é a observação do consumo intenso de personagens midiáticos em mochilas, tênis, roupas, objetos de uso pessoal, que em sua grande maioria ostentavam personagens infantis que iam dos superheróis da Marvel às princesas da Disney, o que reforça também a demarcação do que é concebido como gênero masculino e feminino.

Souza (2000, p 445) lembra que a presença da mídia na vida contemporânea é constante e "[...] o fenômeno mais comum é que se tornam modelos de comportamento e modos de ser para o seu público alvo: todos assistem, imitam e se vestem como os seus ídolos". E as crianças, como 
produtoras de cultura, reinterpretam as mensagens da mídia, incorporando-as em suas práticas cotidianas tais como jogos, atitudes, vestuários, alimentação etc.

Os relatos abaixo ilustram que os acadêmicos observaram uma forte influência da mídia quanto ao consumo de produtos publicitários, que tende a influenciar em comportamentos esperados de meninas e de meninos em prática culturais diversas, inclusive no que tange aos jogos e papéis de gênero. Vejamos:

\begin{abstract}
Alguns possuem mochilas com personagens, como vingadores, incrível hulk, frozen (sic), e há bastante divisão neste sentido, pois as meninas sempre estão com coisas de meninas e os meninos com coisas de meninos. (ACADÊMICOS GRUPO 2)

A influência das mídias é muito forte nas crianças, ela está presente em quase tudo, desde uma simples escova de dente até aos acessórios como roupa com estampas de personagens de super-heróis, na mochila, tênis, lápis de escrever e tantos outros. (ACADÊMICOS GRUPO 4)

Além do acesso às mídias e recursos tecnológicos como a televisão, o vídeo, o rádio, a filmadora, o gravador, a câmera fotográfica, o computador, o tablet e a internet, algumas crianças da turma falam em uso de meios de comunicação digitais e com interação instantânea como o WhatsApp que usam através dos aparelhos dos pais para falar e se comunicar com os avós ou outras pessoas da família gravando vídeos e áudios com o intuito de se comunicar com eles. (ACADÊMICOS GRUPO 6)

Pudemos constatar a influência da grande mídia nas conversas sobre temas variados, onde as crianças comentaram sobre alguns personagens que elas assistem e quais deles eram os seus preferidos. (ACADÊMICOS GRUPO 7)
\end{abstract}

Como se vê, em geral, os olhares de nossos acadêmicos foram sensíveis quanto à percepção do consumo dos elementos midiáticos pelas crianças, chamando a atenção para o quanto esse contexto é similar, embora os três municípios (locus da prática) tenham realidades socioeconômicas bastante diferenciadas. Foi importante constatar nos seus relatos que os materiais teóricos trabalhados nas disciplinas possibilitaram uma abertura do campo de visão dos acadêmicos e que, possivelmente, tenham influenciado nas suas percepções quanto à presença das mídias nos campos de estágio. Essa constatação reforça a importância de se cultivar uma proposta intencional de estudos e problematização do uso de mídias no cotidiano infantil, nos campos de estágios e também nos futuros locais de atuação profissional dos pedagogos.

\title{
CONSIDERAÇÕES FINAIS
}

A partir de uma análise geral dos relatos apresentados pelos acadêmicos, podemos inferir que o modo de ver as mídias, enquanto prática social de adultos e crianças na sociedade contemporânea e, principalmente, nas práticas pedagógicas no campo da educação infantil foi sensibilizado. Consideramos até mesmo que talvez não tivessem tido as mesmas percepções e sensibilidades caso a ida a campo não tivesse sido embasada pelo debate realizado previamente na sala de aula, quando foram estudados e problematizados conceitos e pesquisadores sobre o tema. Para sustentar essa mudança de percepção, teríamos que realizar um estudo comparativo, com grupos de controle, para investigar melhor as percepções com e sem referencial teórico sobre a presença das mídias nesses espaços. Entretanto, como afirmado, o caráter da pesquisa exploratória 
DOI: https://doi.org/10.12957/teias.2020.48632

é realizar aproximações com os fenômenos estudados e delinear novos processos investigativos para aprofundamento da questão. E, ao mesmo tempo que a presente pesquisa limitou seu escopo a algumas aproximações, abriu novos leques de investigação futuras.

Por outro lado, embora tenha se apontado para o olhar sensível dos acadêmicos sobre as mídias no período de leitura de contexto, os projetos de docência ainda trazem as mídias como meros recursos didáticos e não como instituição onipresente. Embora didaticamente as mídias tenham sido utilizadas de forma integrada e alinhada aos objetivos educacionais traçados, com um propósito pedagógico definido, ainda assim, vemos que aparecem no universo docente da educação infantil como recursos, equipamentos e artefatos, muito aquém ainda do que se propõe quando falamos em mídia-educação.

De qualquer maneira, os relatos reforçaram nossa percepção inicial de que é fundamental preparar nossos futuros pedagogos tanto quanto à importância de a mídia ser olhada para além do entretenimento e da necessidade da formação para o uso de tais recursos midiáticos, quanto de sua presença ser uma constante no cotidiano das instituições escolares, principalmente nas escolas de educação infantil, fato ainda subestimado pelo currículo dos cursos de Pedagogia.

Por essas razões, a pesquisa sobre as mídias, mesmo com algumas limitações, mostrou-se bastante promissora e espera-se poder aperfeiçoá-la para inclusão de instrumentos mais apurados para produzir novos dados e analisar as realidades envolvidas e vivenciadas pelos acadêmicos na reflexão e crítica sobre a presença e o uso das mídias na educação.

\section{REFERÊNCIAS}

BAUER, Martin W.; GASKELL, George (orgs.). Pesquisa qualitativa com texto: imagem e som: um manual prático. Petrópolis, Rio de Janeiro: Vozes, 2012.

BELLONI, Maria Luiza. Mídia-educação. In: MILL, D. (org.). Dicionário crítico de educação e tecnologias e de educação a distância. Campinas, São Paulo: Papirus, 2018.

BELLONI, Maria Luiza.; BÉVORT, Evelyne. Mídia-educação: conceitos, história e perspectivas. Educaşão \& Sociedade. Campinas, v. 30, n. 109, set./dez. 2009. p. 1081-1102.

BENJAMIN, Walter. A obra de arte na era de sua reprodutibilidade técnica. Márcio Seligmann-Silva (org.). Trad. Gabriel V. da Silva. Porto Alegre, RS: L\&PM, 2015.

BÖCK, Geisa Letícia Kempfer. O desenho universal para aprendizagem (DUA) e as contribuições na educação a distância. Tese (Doutorado em Psicologia) - Departamento de Psicologia, UFSC, Florianópolis, 2019.

BRASIL. Ministério da Educação. Secretaria de Educação Básica. Base Nacional Comum Curricular. Brasília, Distrito Federal: MEC, SEB, 2017.

BRASIL. Ministério da Educação. Secretaria de Educação Básica. Diretrizes curriculares nacionais para a educação infantil. Brasília, Distrito Federal: MEC, SEB, 2009.

BUCKINGHAM, David. Crescer na era das mídias eletrônicas. Tradução de Gilka Girardello e Isabel Orofino. São Paulo: Loyola, 2007.

BUCKINGHAM, David. Cultura digital, educação midiática e o lugar da escolarização. Educação \& Realidade. Porto Alegre, v. 35, n. 3, set./dez. 2010. p. 37-58. Disponível em: https://seer.ufrgs.br/educacaoerealidade/article/view/13077/10270. Acesso em: 12 mar. 2019. 
BUCKINGHAM, David. Recriando a TV na sala de aula. Entrevista concedida ao site Ateliê da Aurora. Tradução de Gilka Girardello. Florianópolis, Santa Catarina: NICA, 2015. Disponível em: http://www.nica.ufsc.br/entrevistas/entrevista_Buckingham.htm. Acesso em: 12 nov. 2017.

DEMO, Pedro. Pesquisa: princípio científico e educativo. 12. ed. São Paulo: Cortez, 2006, 128p.

FREIRE, Paulo. Pedagogia da Autonomia: saberes necessários à prática educativa. 33 ed. São Paulo: Paz e Terra, 1997.

GIDDENS, Anthony. Modernidade e identidade. Rio de Janeiro: Zahar, 2002.

GIL, Antônio Carlos. Métodos e técnicas de pesquisa social. 6. ed.: São Paulo: Atlas, 2008.

GIRARDELLO, Gilka. Elvira Ponzi; CAMPOS, Karin Coser de. A produção narrativa das crianças no contexto das mídias. Comunicação \& Educação. São Paulo, Ano XVII, n. 2, jul./dez. 2013. Disponível em: http://www.revistas.usp.br/comueduc/article/view/68336. Acesso em: 8 mar. 2019.

GOMES, Nilza Godoy; BELLONI, Maria Luiza. Infância, mídias e aprendizagem: autodidaxia e colaboração. Educação \& Sociedade. Campinas, v. 29, n. 104 - Especial, out. 2008. p. 717-746.

SILVERSTONE, Roger. Por que estudar a mídia? São Paulo: Ed. Loyola, 2002.

SIQUEIRA, Isabelle Borges; WIGGERS, Ingrid Dittrich; SOUZA, Valéria Pereira de. O brincar na escola: a relação entre o lúdico e a mídia no universo infantil. p. 313-326. Revista Brasileira de Ciências do Esporte. Florianópolis, v. 34, n. 2, abr./jun. 2012. Disponível em: http://www.scielo.br/scielo.php?script=sci_arttext\&pid=S0101-32892012000200005. Acesso em: 19 out. 2019.

SOUZA, S. J. et al. A infância na cultura do consumo. Congresso Internacional Os mundos sociais e culturais da infância, 2000, Braga. Anais... Braga: Instituto de Estudos da Criança Universidade do Minho, 2000, v. 3, p. 440-447.

THOMPSON, John B. A mídia e a modernidade: uma teoria social da mídia. 5. ed. Petrópolis, Rio de Janeiro: Vozes, 1998.

UNESCO. Marco de avaliação global da alfabetização midiática e informacional (AMI): disposição e competências do país. Brasília: UNESCO, Cetic.br, 2016.138. Disponível em: https://unesdoc.unesco.org/ark:/48223/pf0000246398. Acesso em: 8 nov. 2019.

VENTURA, Lidnei. O voo da fênix: narrativas de travessias de identidade. Florianópolis: UDESC, 2019.

Submetido em outubro 2019. Aprovado em janeiro 2020. 
DOI: https://doi.org/10.12957/teias.2020.48632

\section{Informações das autoras}

Dulce Márcia Cruz

Professora da Universidade Federal de Santa Catarina, Departamento de Metodologia de Ensino, Universidade Aberta do Brasil e Programa de Pós-Graduação em Educação, Centro de Ciências da Educação (CED)

E-mail: dulce.marcia@gmail.com

ORCID: http://orcid.org/000-0001-7055-0137

Link Lattes: http://lattes.cnpq.br/154334840486505052

Klalter Bez Fontana

Doutoranda em Educação na Universidade Federal de Santa Catarina (UFSC)

E-mail:klalter.fontana@gmail.com

ORCID: https://orcid.org/0000-0003-2536-0777

Link Lattes: http://lattes.cnpq.br/7402731465288377

Lidnei Ventura

Doutor em Educação pela UFSC. Centro de Educação a Distância (UDESC/CEAD)

E-mail: 1liventura@gmail.com

ORCID: https://orcid.org/0000-0003-4310-2632

Link Lattes: http://lattes.cnpq.br/9553407104950703 